\title{
ANÁLISE DO CLIMA E RELEVO NA CONCENTRAÇÃO DE MATERIAL PARTICULADO EM MADRID (ESPANHA) E SÃO PAULO (BRASIL)
}

\author{
SILVEIRA, Thiago Souza - thiagosousilveira@yahoo.com.br \\ Universidade de São Paulo / USP
}

ANTUNES, Roberto Luiz dos Santos - roberto.antunes@fmu.br Centro Universitário das Faculdades Metropolitanas Unidas / FMU

AITH, Fernando Mussa Abujamra - Fernando.aith@usp.br

Universidade de São Paulo / USP

CANTOS, Jorge Olcina - jorge.olcina@ua.es

Universidade de Alicante

GOUVEIA, Nelson - ngouveia@usp.br

Universidade de São Paulo / USP

Submetido em: 04/09/2020

Aceito para publicação em: 21/04/2021

Publicado em: $10 / 05 / 2021$

DOI: http://dx.doi.org/10.5380/abclima.v28i0.76313

\begin{abstract}
RESUMO: $O$ presente estudo pretende examinar as concentrações de material particulado (MP10) e material particulado fino (MP2,5) entre os anos de 2007 e 2018 em São Paulo e Madrid para apontar se as características geográficas, clima e relevo, exercem influência na acumulação desses poluentes. Para isso foram usadas técnicas de geoprocessamento na análise do terreno, dados climatológicos, os boletins de qualidade do ar, as leis sobre poluição atmosférica de cada cidade e as recomendações internacionais sobre o tema. O relevo e o clima das duas cidades são distintos, mas ambos favorecem a concentração de poluição. Ainda assim, nenhuma delas infringiu as legislações locais durante o período, apesar de estarem além do recomendado pela OMS (Organização Mundial da Saúde).
\end{abstract}

PALAVRAS-CHAVE: Poluição do ar; climatologia; geomorfologia; material particulado; legislação ambiental.

CLIMATE AND RELIEF ANALYSIS ON PARTICULATE MATTER IN MADRID (SPAIN) AND SAO PAULO (BRAZIL)

ABSTRACT: This study intends to verify the concentration of Particulate Matter (PM10) and Fine Particulate Matter (PM2,5) between 2007 and 2018 in Sao Paulo and Madrid municipalities to point if geographical characteristics like relief and climate have any influence on air pollution. We used geoprocessing techniques to analyze the landscape, climate data, air quality reports, legislation about the theme of each municipality and the international recommendations about air quality. The relief and climate of both cities are distinct, but able to concentrate air pollution. Despite none of them, during this period has gone beyond the limits of law, they are far from WHO (World Health Organization) recommendations.

KEYWORDS: Air pollution; Climatology; Particulate matter; Environmental laws.

\section{INTRODUÇÃO}

O problema da poluição atmosférica por material particulado é recorrente nos grandes centros urbanos causando diversas consequências para a saúde da população, desde a diminuição da qualidade de vida até ao desenvolvimento de 
doenças graves (ORGANIZAÇÃO MUNDIAL DE SAÚDE, 2011). As principais fontes de emissão de particulados para a atmosfera são: veículos automotores, processos industriais, queima de biomassa e a ressuspensão de poeira do solo (CETESB, 2002). No entanto, as fontes móveis como os automóveis dão a principal parcela de contribuição para o aumento desse poluente, apesar dos avanços tecnológicos na construção de motores, combustíveis e lubrificantes (WORLD HEALTH ORGANIZATION, 1992).

Estes malefícios que a poluição atmosférica causa ao homem e ao meio ambiente já foram largamente estudados e vão desde doenças cardíacas, respiratórias até câncer, além dos danos ambientais como a formação de chuvas ácidas (FERREIRA, FORTI, et al., 2016) (NARDOCCI, FREITAS, et al., 2013) (VIEIRA-FILHO, LEHMANN e FORNARO, 2015) (NEWELL, KARTSONAKI, et al., 2017) (AMATO-LOURENÇO, MOREIRA, et al., 2016).

Cabe destacar que além das citadas enfermidades cardiorrespiratórias, de acordo com a Agência Internacional de Pesquisa sobre Câncer (IARC ${ }^{1}$ ), a concentração de material particulado grosso e fino $\left(M_{10}\right.$ e $M_{12,5}$, respectivamente) fazem parte do grupo 1 dos agentes carcinogênicos, ou seja, os mais perigosos à saúde (PEREIRA, LEMOS, et al., 2011) (NEWELL, KARTSONAKI, et al., 2017) (HAMRA, GUHA, et al., 2014) (LOOMIS, HUANG e CHEN, 2014).

Por conta de todos esses problemas em potencial, muitos países se comprometem a limitar e fiscalizar os níveis de emissão e concentração de poluentes do ar, como por exemplo, o Brasil e a Espanha (UNITED NATIONS, 1998). Portanto, para o Estado regular a qualidade do ar é necessário primeiramente que haja um comprometimento dele em prover um meio ambiente preservado aos seus cidadãos, definir os limites de poluição por leis específicas e possuir uma rede de estações de aferição da qualidade do ar. Nesse caso, os dois países já assinaram tratados internacionais sobre o tema como o do Mercosul e a da União Europeia e montaram suas redes de aferição de poluentes (MERCOSUL, 2001) (EUROPEAN COMMISSION, 2008). Além disso, estabeleceram os limites de materiais particulados $M_{10}$ e $M_{2,5}$ de respectivamente, 120 e $50 \mu \mathrm{g} / \mathrm{m}^{3}$ para média anual e $40 \mu \mathrm{g} / \mathrm{m}^{3}$ - para ambos, de média em 24 horas. Ainda assim são metas longe das recomendadas pela OMS que são: para $\mathrm{MP}_{10} 20$ e $50 \mu \mathrm{g} / \mathrm{m}^{3}$ (anual e diária) e para $\mathrm{MP}_{2,5} 10$ e 25 (anual e diária) (ORGANIZAÇÃO MUNDIAL DE SAÚDE, 2018).

Considerando que as cidades de São Paulo (Brasil) e Madrid (Espanha) apresentam diferenças na regulação da concentração de poluentes e nas suas características geográficas, 0 estudo do comportamento dos materiais particulados nessas áreas urbanas se torna fundamental para compreender tanto a dinâmica dos contaminantes quanto a forma com que cada lugar lida com o problema.

Estas características geográficas do sítio urbano como o clima, relevo ou sua densidade populacional podem influenciar na concentração e dispersão de poluentes, que é definida como alterações químicas e físicas do estado natural da atmosfera (ORGANIZAÇÃO MUNDIAL DA SAÚDE, 2005). Muitas cidades no Brasil possuem controle de qualidade do ar e São Paulo se destaca por ser a

\footnotetext{
${ }^{1}$ International Agency for Research on Cancer - United Nations
} 
maior metrópole do país, assim como Madrid, na Espanha. Coincidentemente, nas duas cidades o problema de poluição do ar já é considerado um perigo para a saúde da população (GOUVEIA, FREITAS, et al., 2006) (RÍOS, 2019).

Em geral a partícula de poluição, após sua emissão, fica em suspensão na atmosfera seguindo principalmente os movimentos de circulação do ar, que por sua vez são influenciados pelo relevo e pelo uso do solo, nesse caso, o tamanho da área urbanizada. Esses fatores ajudam a determinar a extensão e a concentração da pluma de poluição, que pode durar de algumas horas até dias, a depender do sistema atmosférico atuante (OKE, 1987) (MENDONÇA e DANNIOLIVEIRA, 2009) (STEINKE, 2012).

A densidade da área urbana está relacionada com o relevo, logo o potencial de concentração de fontes de emissões está relacionado com o potencial de dispersão da poluição. Assim, áreas urbanas densas em condições de estabilidade atmosférica e com relevos trabalhados são os lugares preferenciais para persistência de má qualidade do ar (CASTRO, 1993) (MENDONÇA e MONTEIRO, 2003).

Neste contexto, o objetivo deste estudo é examinar as concentrações de material particulado fino $\left(\mathrm{MP}_{2,5}\right)$ e material particulado grosso $\left(\mathrm{MP}_{10}\right)$ entre os anos de 2007 e 2018 em São Paulo e Madrid para apontar se as características geográficas, clima e relevo, exercem influência na acumulação desses poluentes.

Neste caso, intenta-se apontar se no clima das duas cidades há, em alguma época do ano, condições que favoreçam a concentração desses poluentes $\left(M_{10}\right.$ e $\left.M_{2,5}\right)$ na mesma bacia atmosférica. Com relação a geomorfologia objetiva-se descrevê-la para saber se a orientação, altitude topográfica e a densidade populacional influenciam na concentração da poluição. $\mathrm{E}$, finalmente, verificar se os níveis de poluição do ar estão atendendo os padrões estipulados por suas respectivas legislações de qualidade do ar e as recomendações da OMS sobre o tema.

\section{MATERIAIS E MÉTODOS}

O desenvolvimento de cada uma das etapas previstas nesta pesquisa foi importante para que os objetivos propostos fossem alcançados. Neste sentido, a investigação da concentração de material particulado se estruturou em dois vieses: a análise dos fatores geográficos (clima e relevo e suas repercussões na área urbana) e a verificação do cumprimento da legislação em relação aos parâmetros exigidos. O fluxograma abaixo esquematiza as principais etapas realizadas (FIGURA 1 ). 


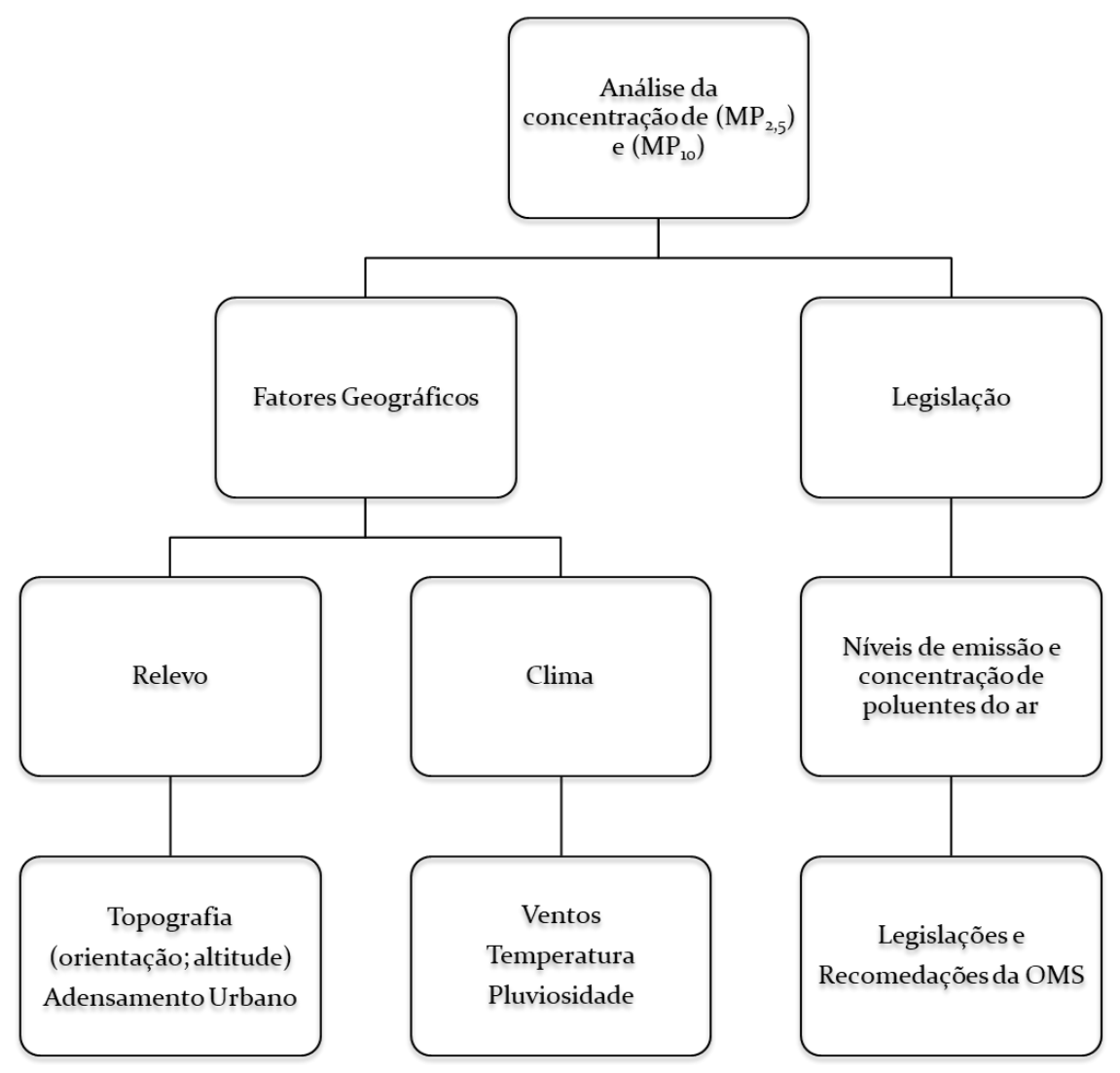

Figura 1 - Fluxograma das etapas da pesquisa

\section{1 ÁREA DE ESTUDO}

A escolha das cidades como área de estudo seguiu algumas condições: os Estados estarem comprometidos com o meio ambiente, em específico na regulação dos níveis de material particulado; ter uma área urbana significativa; disponibilidade de relatórios com informações sobre a qualidade do ar, dos aspectos geográficos da cidade e da rede de aferição dos poluentes.

Quanto aos dados político-administrativo de cada cidade, com o intuito de compreender os territórios em estudo, consultou-se o geoportal da cidade de São Paulo (GeoSampa) (PREFEITURA DE SÃO PAULO, 2013) e o portal de Datos Abierto del Ayuntamiento de Madrid (AYUNTAMIENTO DE MADRID, 2010).

\subsection{FATORES GEOGRÁFICOS: CLIMA E RELEVO}

Os fatores geográficos analisados tanto na sua espacialidade quanto na temporalidade do evento, foram: o clima e o relevo. Desta forma, analisaram-se os aspectos geomorfológicos de cada cidade por meio de revisão bibliográfica, verificando os patamares topográficos e a disposição das principais vias, associando-as a morfologia urbana e aos fatores de concentração urbana.

O sítio da NASA foi utilizado para adquirir as imagens de SRTM - Shuttle Radar Topography Mission, com resolução espacial de 30 metros para saber 
como é o relevo das duas cidades (EMBRAPA, 2005) (NATIONAL AERONAUTICS AND SPACE ADMINISTRATION, 2009).

Esta análise do relevo permitiu a interpretação da influência topográfica, considerando o adensamento urbano, as formas de ocupação ao longo do tempo e a morfologia do terreno onde as referidas cidades estão assentadas. Uma breve contextualização geológica também foi necessária para o entendimento da disposição topográfica.

Os dados climatológicos foram obtidos nos sítios do Climate Data (CLIMATE DATA, 2006) e do NOAA, NCEP/NCAR (NOAA, 2013). Dentro do contexto climatológico de cada cidade, alguns elementos se destacam por conta de seu potencial para levar ao acúmulo de poluentes, por exemplo: pluviosidade, temperatura e ventos, analisados sob a ótica do ritmo climático local e a dinâmica atmosférica.

Com a reunião de todos estes dados e informações foi possível identificar as relações dos fatores geográficos com a disposição do material particulado nas áreas de estudo. A caracterização geológica/geomorfológica foi fundamental para entender a disposição das vias de circulação e da ocupação urbana relacionando-as à concentração e a dispersão do material particulado.

\subsection{OS REGISTROS DE MATERIAL PARTICULADO}

Os relatórios e a legislação de qualidade do ar, assim como os dados climatológicos estão disponibilizados nos sítios da CETESB (Companhia Ambiental do Estado de São Paulo) para a cidade de São Paulo e no Portal Web de Calidad del Aire del Ayuntamiento de Madrid (CETESB, 2009) (AYUNTAMIENTO DE MADRID, 2010). Nesses documentos estão registradas as médias anuais, as máximas em 24 horas de material particulado de cada estação, além da sua localização com coordenadas e a representatividade dos dados coletados. Totalizando entre 8 a 12 estações para São Paulo e cerca de 19 para Madrid para os anos estudados.

\section{RESULTADOS E DISCUSSÃO}

Os dados, informações e as análises obtidas na pesquisa estão estruturados em três partes: a primeira compreende o estudo da influência do relevo nas cidades, a segunda parte refere-se ao comportamento climático atuante para a concentração de material particulado. A terceira parte relacionase a verificação do cumprimento dos níveis de emissão e concentração dos poluentes do ar nas duas cidades, a partir da análise das leituras dos relatórios de qualidade do ar e das legislações.

\subsection{A INFLUÊNCIA DO RELEVO DE MADRID E SÃO PAULO:}

Esta análise subdivide-se na verificação da influência da ocupação urbana e nos processos de formação do relevo e a concentração de poluentes em São Paulo_e Madrid. 


\subsubsection{CONCENTRAÇÃO URBANA}

As condições fundamentais para seleção e análise das cidades foram satisfatórias. Ambas as cidades são regiões metropolitanas de grande importância nos seus respectivos países, com elevada concentração populacional de São Paulo e Madrid, o que reflete nos altos índices de urbanização, corroboradas pela alta densidade populacional de 5418 hab./ $\mathrm{Km}^{2}$ para Madrid e $7387 \mathrm{Hab} . / \mathrm{Km}^{2}$ em São Paulo, com uma área de $604,3 \mathrm{Km}^{2}$ e $1521 \mathrm{Km}^{2}$ respectivamente (IBGE, 2011) (INSTITUTO NACIONAL DE ESTADÍSTICA DE ESPAÑA, 2018).

Político-Administrativamente os territórios são divididos de forma diferente, enquanto no Brasil funciona na ordem crescente município, estado, país; na Espanha é município, província, país. A partir do levantamento desses dados, foi possível identificar a localização das áreas de estudo e ao mesmo tempo, foi a base para confecção de novos mapas como o de relevo, localização das estações de qualidade do ar e principais vias das cidades.

Os problemas de qualidade do ar são uma das características negativas que estes grandes centros urbanos apresentam, relacionados à grande densidade populacional, industrialização acentuada, e com grande frota veicular (SILVA JUNIOR, MARTILLI e SILVA, 2020). Inseridas neste contexto, São Paulo e Madrid possuem áreas extensas com população conurbada. São Paulo possui um parque industrial amplamente desenvolvido, refletindo na emissão e concentração de poluentes. Já Madrid não possui atividade industrial relevante nas proximidades e a poluição pode ser considerada tipicamente urbana (GÓMEZ-MORENO, NÚÑEZ, et al., 2007).

Em ambas as cidades a densidade da área urbana contribui para a concentração de poluentes o que pode ser evidenciado em estudos realizados sobre o tema nas duas cidades. Silva Júnior (2009, p. 154), identificou através de modelagens atmosféricas que há uma diminuição na intensidade do vento em $1,5 \mathrm{~m} / \mathrm{s}$ sobre a zona urbana, caracterizando uma desaceleração da velocidade do vento devido à presença das construções. Esta desaceleração contribui para a concentração dos poluentes com as edificações servindo de barreira física para a dispersão do material particulado.

García et al. (1996, p. 478) destaca um perfil térmico longitudinal em Madrid que identificou as influências topográficas e urbanas nas temperaturas. Descrevem que "o ar frio é canalizado pela rua e aquece à medida que entra na zona urbana, o que determina a formação de uma ilha de calor claramente diferenciada neste setor", o que contribui para a elevação dos índices de concentração de poluentes na área central da cidade de Madrid na ressuspensão dos materiais particulados.

\subsubsection{PROCESSOS DE FORMAÇÃO DO RELEVO E A CONCENTRAÇÃO DE POLUENTES}

As características do relevo das cidades de São Paulo e Madrid são distintas, com processos de formação diferenciados, devido sobretudo às relações endogenéticas e a ação dos agentes intempéricos responsáveis pela modulação das formas de relevo. Justamente a análise da geologia fará com que 
as formas assumidas pelo relevo em cada local tenham sentido, pois a conformação dele dependerá bastante do seu material de formação.

A capital paulista está inserida praticamente dentro da Bacia Sedimentar de São Paulo, distinguindo-se três compartimentos diferenciados quando se analisa a estrutura geológica da cidade, que inclui a própria bacia sedimentar, o seu rebordo e os depósitos aluviais dessa bacia.

Esta bacia, com idade do terciário tem seu rebordo constituído basicamente por formação graníto-xisto-gnaíssico, cortado por um sistema précambriano de falhamentos reativado em um sistema de blocos e cunhas em degraus, situado no limite norte, na região do Pico do Jaraguá, representado pela maior elevação da cidade. Na parte interna da bacia, identificam-se as coberturas aluviais e colúvios quaternários, que compreende toda a região do centro expandido, visto nas áreas centrais até as marginais dos rios Tietê e Pinheiros, e os extremos oeste e leste, do bairro do Jaguaré ao Itaim Paulista, já do outro lado das margens desses rios (PELOGGIA, 1998).

Os sedimentos terciários da Bacia Sedimentar de São Paulo são identificados em toda a área central da cidade, bem como ao longo da margem esquerda do rio Tietê e em manchas isoladas ao sul, ao norte (região de Santana) e no Sudoeste (PREFEITURA DA CIDADE DE SÃO PAULO, 2004). Assentado nesta estrutura geológica, tem-se a atuação dos processos intempéricos que modelaram o relevo de São Paulo, com poucas áreas de elevadas altitudes, como o Pico do Jaraguá (1221 metros), e a Serra da Cantareira ao Norte, além das elevações que limitam a região metropolitana: a Serra do Mar à leste, a Serra de Paranapiacaba ao sul.

Geomorfologicamente a área do município de São Paulo compreende um sistema de colinas, terraços e planícies na confluência dos rios Tietê e Pinheiros, que são os principais cursos d'água da cidade (AB'SABER, 2007). É a partir das colinas que grande parte da cidade se desenvolveu, sendo que a infraestrutura urbana foi se intensificando, abrindo caminho nestas formas de relevo, com a inserção de túneis, viadutos, avenidas radiais, que se dispõem justapostas a estas áreas.

Contando que a cidade se desenvolveu em direção às margens dos rios, ou seja, "descendo" as encostas, os aparatos urbanos também se espalharam para as partes mais baixas, dificultando a circulação do ar que além do pico do Jaraguá que é mais alto, porém desocupado, passou a ter também os espigões como barreira para escoamentos, mais baixos, mas densamente ocupados. Justamente esta configuração de relevo de São Paulo, um planalto de cerca de $750 \mathrm{~m}$ rodeado por terras mais altas, de até $1200 \mathrm{~m}$ (FIGURA 2), que contribui para a concentração local de poluentes, uma vez que as serras no entorno potencialmente podem agir como barreiras físicas que dificultam a sua dispersão (FRUEHAUF, 1998).

Esta topografia impõe resistência ao escoamento atmosférico, reduz a velocidade do vento e impede que a brisa marítima avance (FARIAS, 2013). Neste contexto, em estudo sobre análise espacial sobre a qualidade do ar da bacia aérea da região metropolitana do Rio de Janeiro, Oliveira (2004) verificou que a orientação e a altitude da topografia na área de estudo influenciam a direção e a velocidade dos ventos de superfície, facilitando ou dificultando a diluição e dispersão de gases e partículas em alguns pontos da bacia aérea. 
Sobre esta questão Farias (2013, p. 48) observou que em todas as simulações realizadas em seu estudo os poluentes deslocaram-se em baixa altitude no início do percurso, sem conseguir ultrapassar os 100 metros de altitude, fato que foi utilizado como comprovação do efeito do relevo enquanto barreira física, impedindo a ação dos ventos.

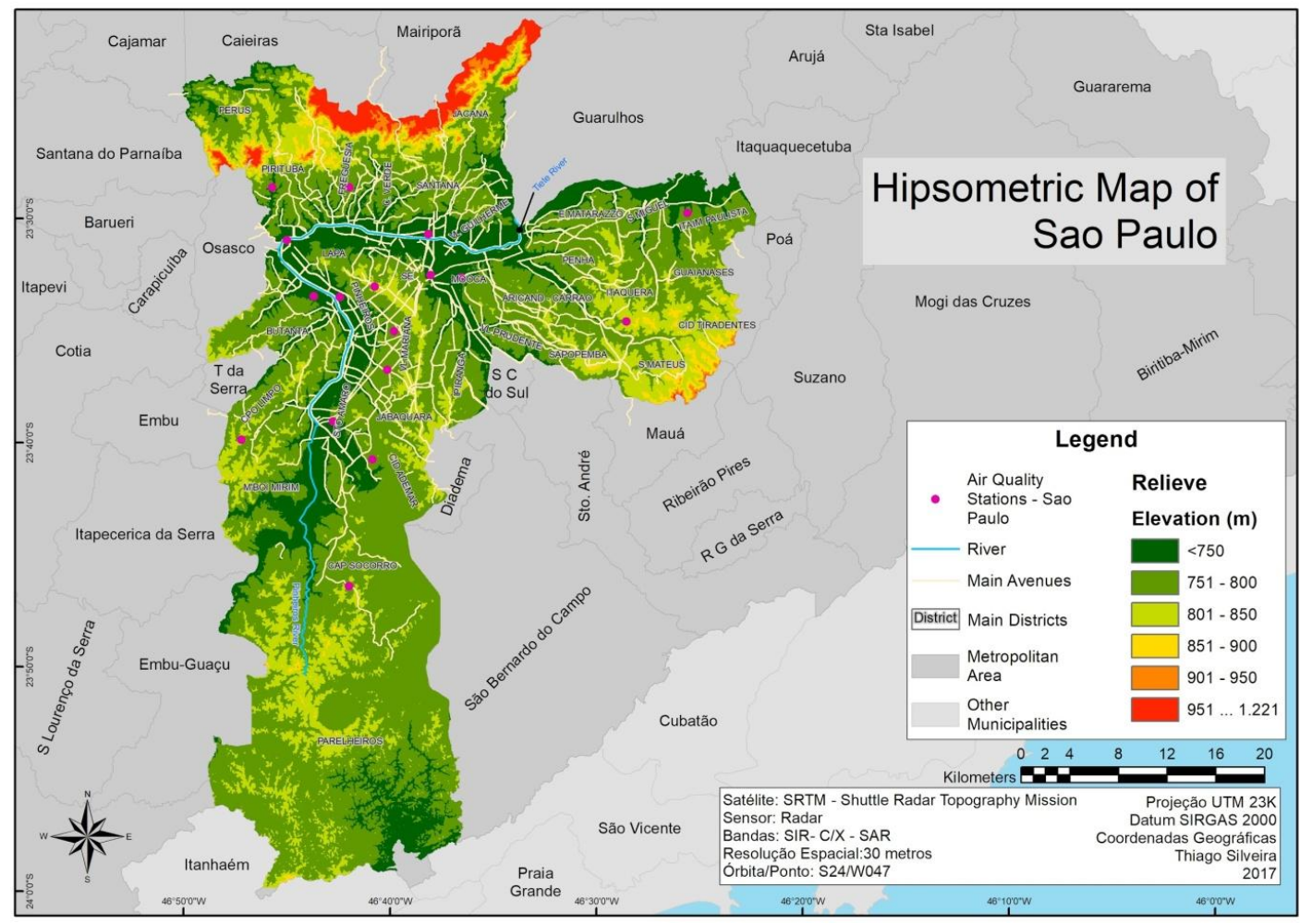

Figura 2 - Relevo, estações de qualidade do ar de São Paulo

Justamente sobre a velocidade do vento, Torres e Martins (2005) identificaram uma rigorosa ligação entre a concentração de material particulado inalável $\left(\mathrm{MP}_{10}\right)$ com a velocidade do vento em Juiz de Fora (MG), e concluíram que quanto menor for a mesma, maior é a concentração, mantidas as condições de direção do vento idênticas. Os autores (p. 32) identificaram que "o período de menor concentração de partículas se deu no momento em que a velocidade do vento era maior e à noite, quando a velocidade do vento cai, observaram um aumento considerável da concentração de poluentes".

A direção do vento também é influenciada pela topografia do terreno e a orientação do relevo. Observa-se que enquanto as avenidas de Madrid passam predominantemente pelo planalto, depois da várzea do rio Manzanares; em São Paulo as principais avenidas passam pelas margens dos rios, ocupando os vales. Esses locais mais baixos e com vias de circulação de automóveis são predominantemente áreas concentradoras de poluição, pois a circulação de ar fica restrita a apenas uma direção, definida pelo relevo.

Esta influência dos compartimentos topográficos na concentração de poluentes também se relaciona às características geológico-geomorfológicas da Comunidade de Madrid (que equivale a um estado no Brasil), do qual a Ciudad 
de Madrid faz parte, destacando-se duas regiões fisiográficas, a Serra e a Depressão.

La Sierra, como é denominada, constitui a frente montanhosa da parte noroeste da Comunidade de Madrid, como resultado do renascimento tectônico de uma antiga penillanura (peneplanície), produzida essencialmente durante o terciário, que se subdivide em Cumbres (cimeiras), que possuem as Cuerdas e as Parameras Serranas, com altitudes entre 1.200 e 1.700 metros e as Vertientes, se subdividem em Laderas, que são as escarpas e os Piedemontes 0 Rampas (GARCÍA ALVARADO e SOTELO NAVALPOTRO, 1999).

Dentro desta caracterização, a Ciudad de Madrid, que se situa na parte central da Comunidade, compreende principalmente as vertentes e os fundos de vale e nos seus extremos (Leste e Oeste) assenta-se sobre as divisórias. Em menor abrangência, mas com ocorrência no município estão os Paramos e Plataformas, na parte sul da cidade (PEDRAZA, CARRASCO, et al., 2002).

A área metropolitana de Madri faz fronteira com Serra de Guadarrama, uma cordilheira alta, a $40 \mathrm{~km}$ de cidade ao norte-noroeste e pelas montanhas mais baixas o terreno para nordeste e leste (GÓMEZ-MORENO, NúÑEZ, et al., 2007). Desta forma, assim como São Paulo esta barreira física contribui para a concentração de poluentes, pois a atuação deste relevo influencia a orientação e a velocidade do vento. Especificamente em relação ao relevo da cidade destacase uma faixa central na cidade, de Norte a Sul, que acompanha o entorno da Autopista M-30, cujas altitudes estão entre 550 e 650 metros. A partir desta área, as altitudes crescem em direção às bordas, principalmente na parte norte da cidade, onde situam-se algumas áreas isoladas que chegam a 850 metros (FIGURA 3).

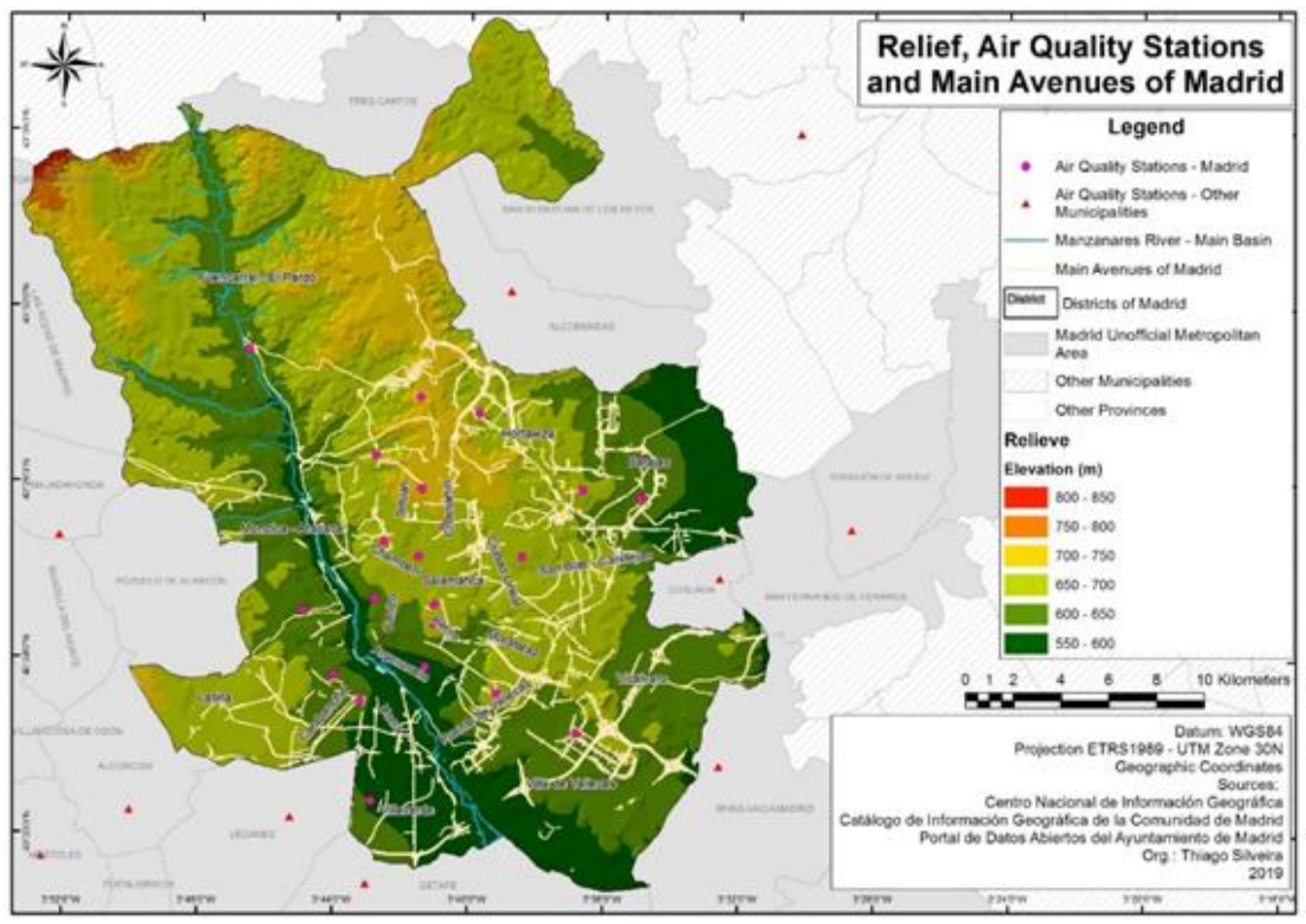

Figura 3 - Relevo, estações de qualidade do ar de Madrid 
No sul de Madrid as elevações são menores do centro em direção ao Sul (até Villa de Vallecas) (GARCÍA ALVARADO e SOTELO NAVALPOTRO, 1999). Neste contexto pode-se associar a característica da ocupação urbana, cuja concentração está em grande parte localizada nestas áreas que possuem menores altitudes e declividades relativamente baixas. Destacam-se também as áreas localizadas na porção leste, depois da Autopista M-30, se caracteriza pela presença de colinas e pequenos morros com altitudes médias entre 700 e 750 metros.

Com esta característica dos relevos da cidade, pode-se associar à deposição, concentração e a distribuição do material particulado. Portanto, tendo conhecimento do relevo, da localização e da densa área urbana, o clima é o último fator a ser analisado. A morfologia urbana é em grande parte responsável pela concentração de poluentes, devido a formação das chamadas bacias aéreas em encostas de até 100 metros, pois acima desta altitude os poluentes iniciam o processo de dispersão (FARIAS, 2013).

Neste sentido, a partir da caracterização topográfica verificou-se a presença de baixas altitudes na parte central das cidades e patamares mais elevados em suas áreas limítrofes. Este fato, remete à localização das vias de circulação justapostas aos vales em ambas as cidades, que são por excelência, áreas de forte incidência de inversões térmicas e por isso de condições privilegiadas de acumulação de poluentes (YOSHINO, 1984).

Nota-se ainda no mapa que o desenvolvimento da cidade de Madrid, apesar de ocupar o vale do rio Manzanares, a área de menor altitude, não onde está o core da cidade, sendo preferencialmente ocupada no seu planalto, entre as cotas de 600 e 700 metros, verificada pela concentração das avenidas principais. Isso auxilia a circulação do ar ainda mais porque a leste, perto da área de Barradas, também há um declínio de altitude. Logo, apesar das regiões de elevadas altitudes ao norte, a calha do Rio Manzanares onde há a autopista (via de trânsito rápido) e a área depressiva a leste, o core da cidade está num planalto à meia altura com depressões à volta.

Por esta característica pode-se considerar que em parte a cidade está submetida a condições de concentrações de material particulado significativo nas áreas com elevações topográficas médias, representadas pelas colinas e formas de relevo mais baixos e outras cuja elevações são maiores, indicando que, devido a uma maior circulação dos ventos, uma maior dispersão dos poluentes. Contudo, a barreira física da Serra de Guadarrama, a circulação de veículos e a densidade urbana contribuem para que o material particulado se concentre neste local.

\subsection{O CLIMA NAS CIDADES DE MADRID E SÃo PAULO}

Na parte climática, em ambas as cidades foram elaborados climogramas com os dados do sítio Climate Data, onde as linhas mostram as médias das temperaturas e as colunas as médias das precipitações na cidade em 30 anos, mês a mês (FIGURA 4) (FIGURA 5). 


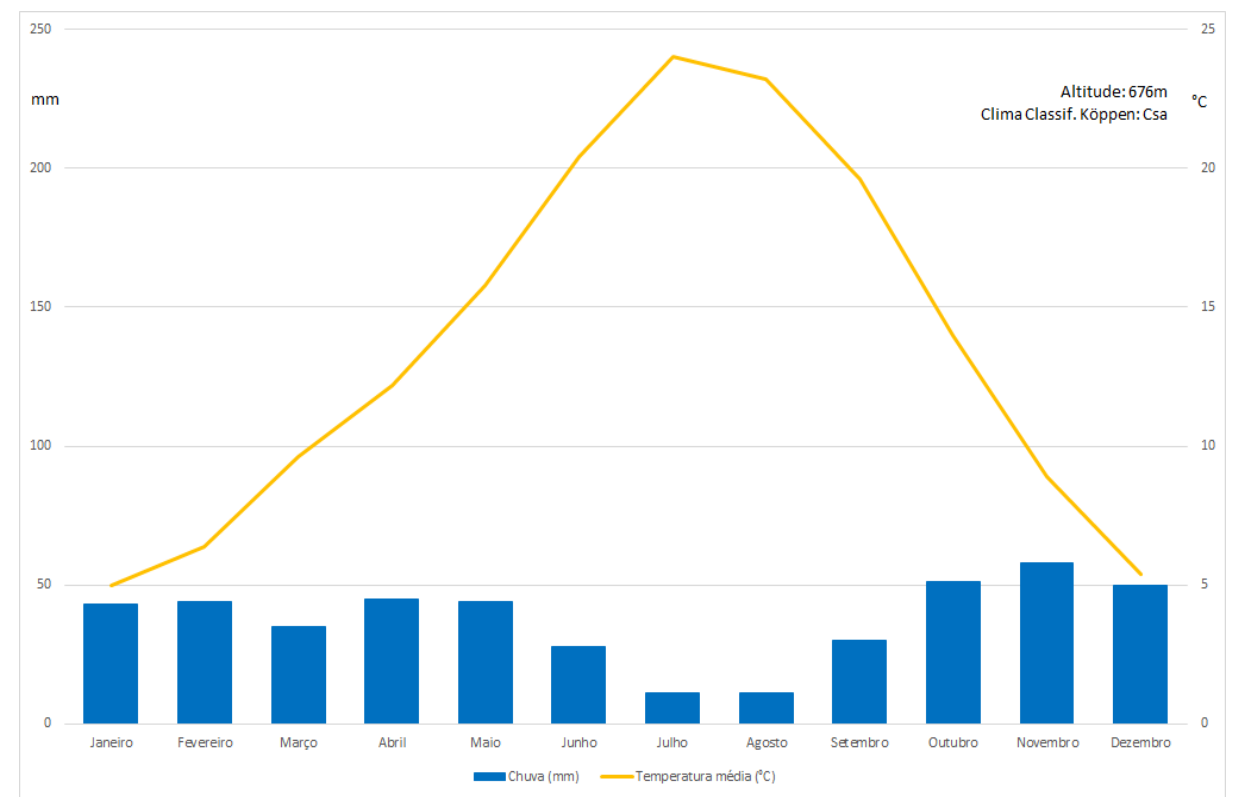

Figura 4 - Climograma de Madrid 1982-2012 Fonte: Climate-Data.org. Adaptação: Autor

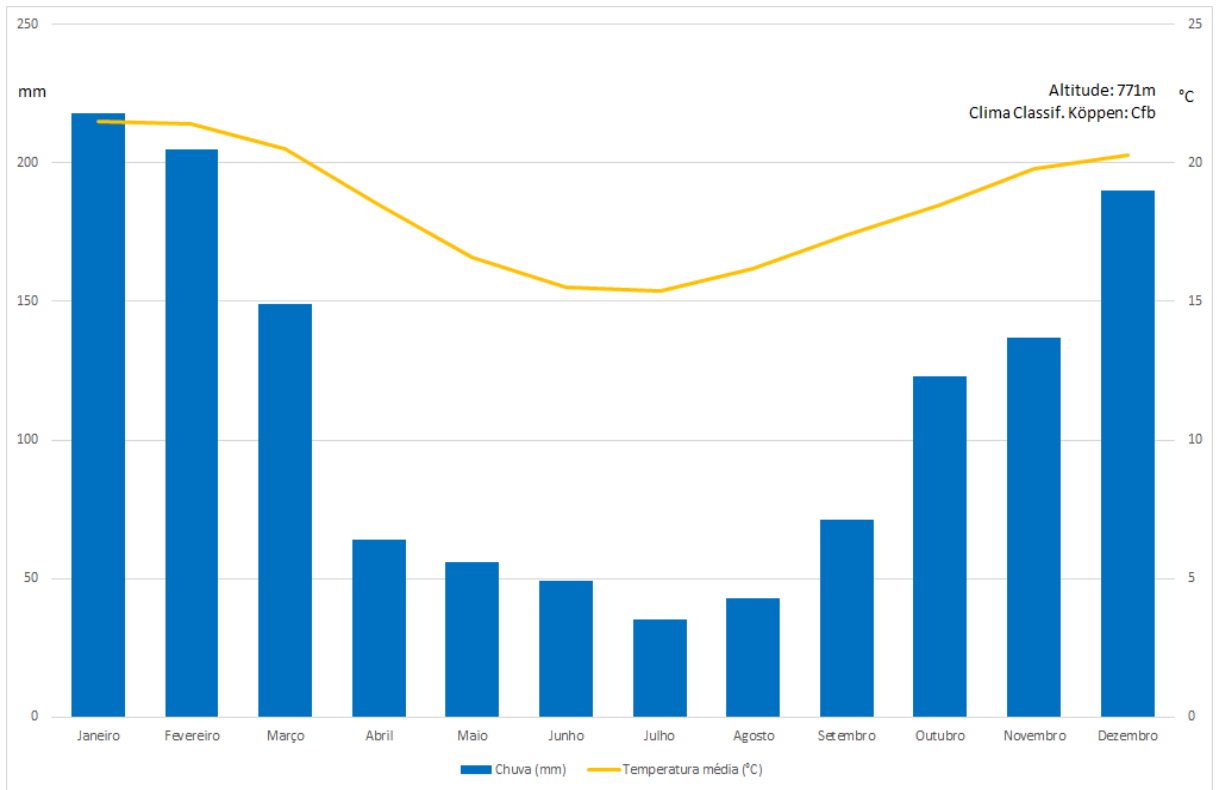

Figura 5 - Climograma de São Paulo 1982-2012. Fonte: Climate-Data.org. Adaptação: Autor

As cidades apresentam diferenças climáticas de médias de temperatura e pluviosidade, assim como apresentam uma estação seca no verão, no caso europeu e sem estação seca em São Paulo, mas com redução significativa do volume de chuva no inverno. Apesar de chover menos em Madrid, comparativamente, há melhor distribuição ao longo do ano. Quanto às temperaturas, há uma variação bem marcante entre as estações quente e fria para Madrid e menos para São Paulo, variando entre 16 e $22^{\circ} \mathrm{C}$. 
Em outra análise, pela classificação Köppen - o clima em Madrid é temperado úmido com verão quente (Csa) e seco e São Paulo clima oceânico temperado sem estação seca (Cfb). A altitude da cidade latina é maior, proporcionando verões frescos, corroborando a análise inicial.

A frequência da pluviosidade indica o poder de lavagem da atmosfera (washout) que cada sítio possui através da distribuição de chuva e neve, uma vez que a água pode ser um núcleo de condensação e atrair e precipitar o material particulado da atmosfera (MENDONÇA e DANNI-OLIVEIRA, 2009) (LANDSBERG, 1983). Na comparação, Madrid apresenta uma distribuição melhor de chuvas ao longo do ano, sendo assim, melhor frequência de limpeza da atmosfera por ocorrer de forma uniforme. Em São Paulo elas se concentram predominantemente na primavera e verão (outubro a março), deixando muitas partículas suspensas nos outros meses.

A cidade espanhola apresenta também temperaturas variadas ao longo do ano, no verão (julho a setembro) há ventos fracos de sul e a pressão atmosférica tende a se estabilizar nessa época do ano, podendo acumular mais material particulado, deixando a atmosfera mais poluída, e como há menos chuvas nesses meses, logo, há menos limpeza também, sendo esses os meses mais críticos para os níveis de material particulado. Por outro lado, o inverno frio e com muitos dias de neblina (GIL OLCINA e OLCINA CANTOS, 2017, p. 642) estimulam as pessoas ficarem em locais fechados e propensas às doenças respiratórias (SALDIVA, 2018) e a poluição atmosférica indoor (SALTHAMMER, SCHRIPP, et al., 2014) principalmente pelo sistema de aquecimento doméstico.

No entanto, o que se deve ressaltar nas condições invernais para Madrid é a atuação sinótica de anticiclones de origem polar por vários dias, causando estabilidade atmosférica e, algumas vezes, o próprio bloqueio atmosférico, onde a parcela de ar não se renova e acumula material particulado e outros poluentes ao longo dos dias (FIGURA 6). Essa situação só cessa quando os ventos atlânticos, de oeste e noroeste, conseguem transpor o anticiclone limpando o ar da cidade dispersando os contaminantes (FIGURA 7). 


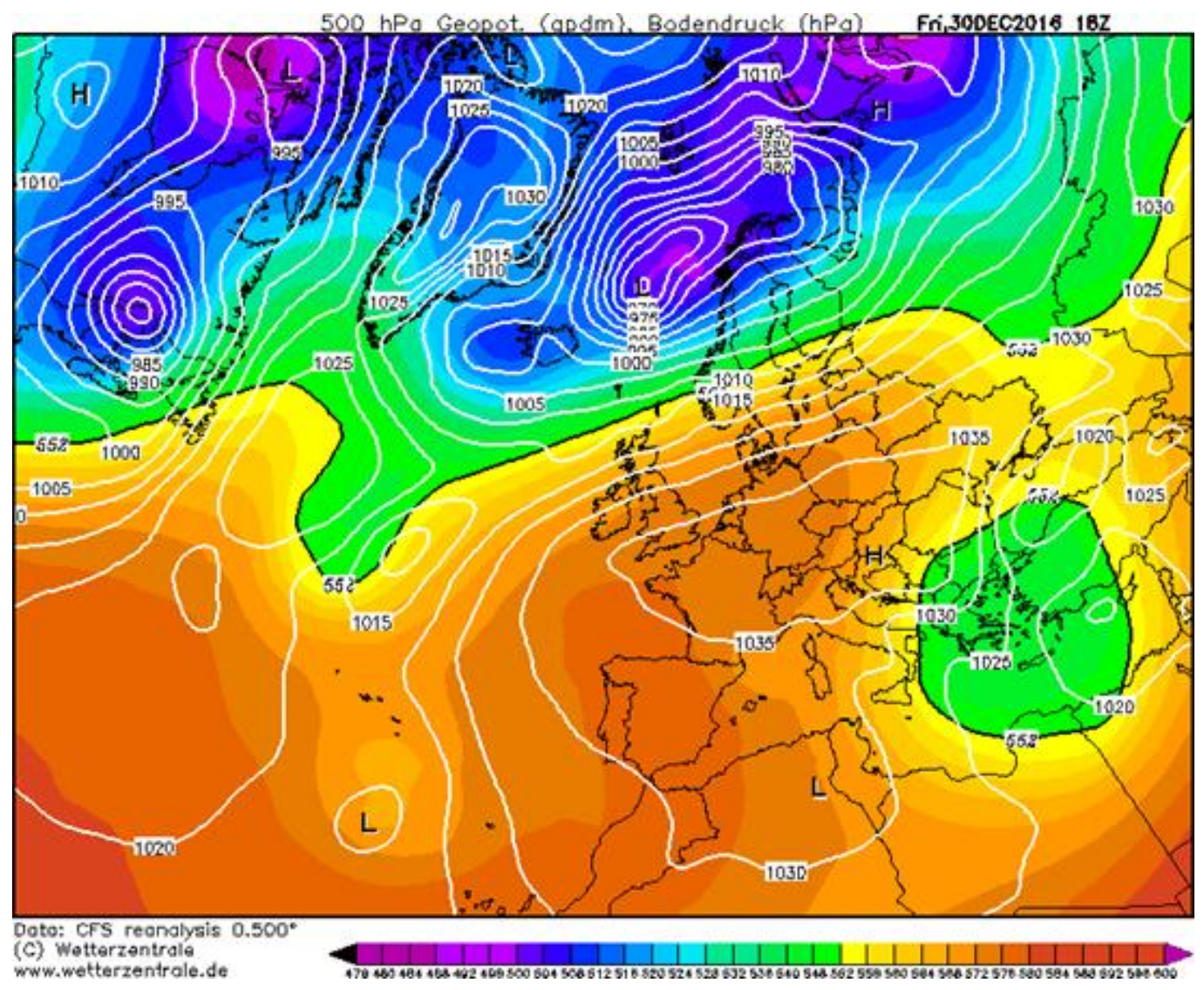

Figura 6 - Situação Anticiclônica invernal causadora de altos níveis de poluição em Madrid (30/Dez/2016). Fonte: Wetterzentrale.de

O vento ainda pode alterar as condições de qualidade do ar quando está sob influência do oceano Atlântico ou do ar tropical continental Sahariano, que fica no norte da África durante o verão, soprando de sentido sul e sudoeste através da região da Andaluzia (GIL OLCINA e OLCINA CANTOS, 2017). Em algumas condições atmosféricas esses ventos podem carregar os sedimentos do deserto e contaminar a atmosfera de Madrid (DIRECCIÓN GENERAL DE SOSTENTABILIDAD Y CONTROL AMBIENTAL, 2018). Porém no inverno há maior influência do oceano ártico, com ventos mais frequentes e mais frios, como mostrado pelos dados de reanálise atmosférica do NOAA - NCEP/NCAR (FIGURA 6) (NOAA, 2013) no efeito de varrição das partículas. Por vezes, os ventos vêm do continente e atingem a cidade, causando ondas de frio rigorosas (GIL OLCINA E OLCINA CANTOS, 2017). 
NCEP/NCAR Reanolysis

Surface Vector Wind $(\mathrm{m} / \mathrm{s})$ Composite Mean

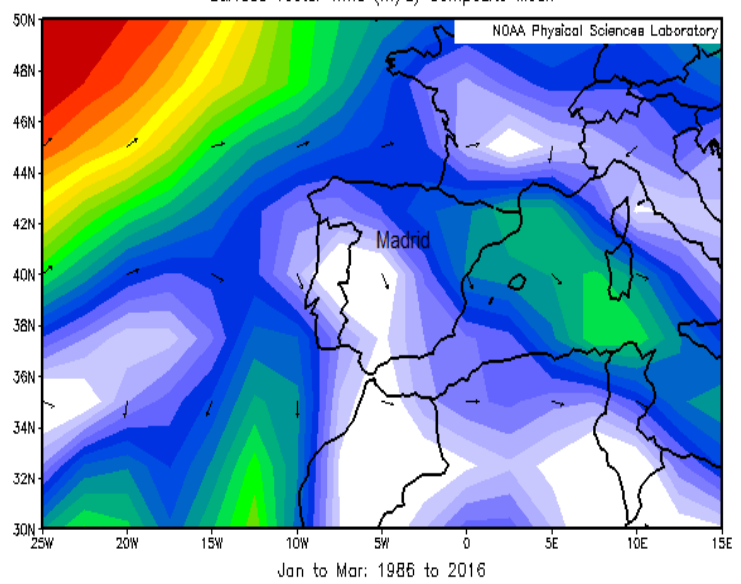

Jon to Mar: 1986 to 2016

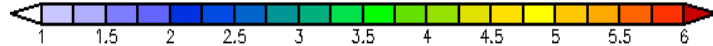

NCEP/NCAR Reanolysis

Surface Vector Wind $(\mathrm{m} / \mathrm{s})$ Composite Mean
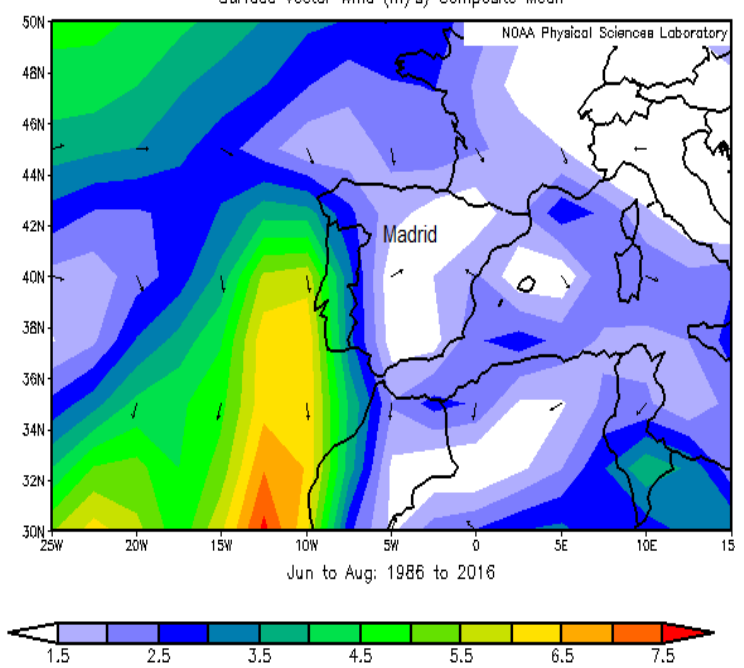

Figura 7 - Mapa de média de direção e intensidade ventos para Espanha Verão (direita) e inverno (esquerda). Fonte: NCEP/NCAR

Em São Paulo, durante o verão, a cidade sofre influência da massa equatorial tropical, que fica na Amazônia e carrega muita umidade e ventos quentes para o município, onde por sua vez encontra condições de chuvas torrenciais na cidade. No inverno, a massa polar atlântica sul vinda do sul do país diminui as temperaturas e chuvas de frentes frias são ocasionais na cidade. Por causar tempo estável de temperaturas baixas, a camada limite fica mais perto da superfície, o ar mais denso e eventos de inversão térmica propícios a ocorrer, piorando a qualidade atmosférica (CAVALCANTI, FERREIRA, et al., 2009) (TARIFA e AZEVEDO, 2001) (FIGURA 8).

NCEP/NCAR R日anolysis

Surface Vector Wind $(\mathrm{m} / \mathrm{s})$ Composite Mean
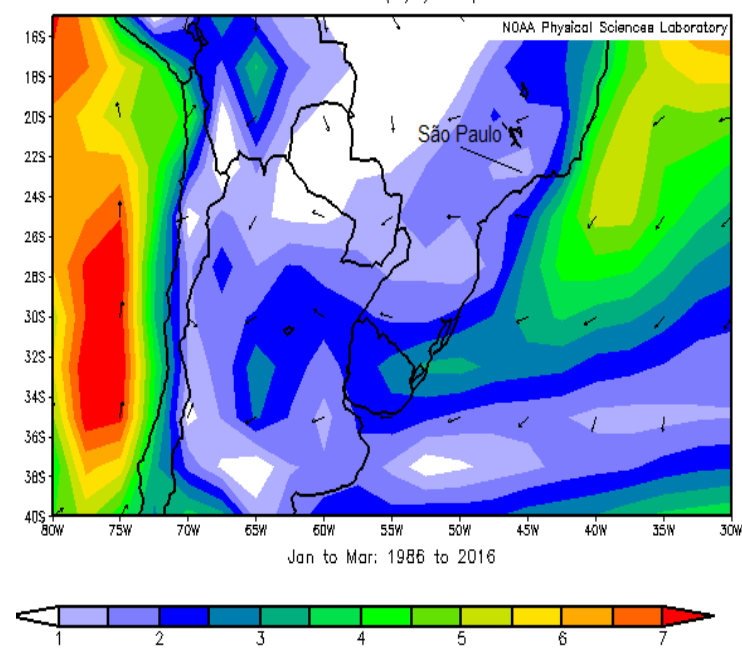

NCEP/NCAR Roanolysis

Surface Vector Wind $(\mathrm{m} / \mathrm{s})$ Composite Mean
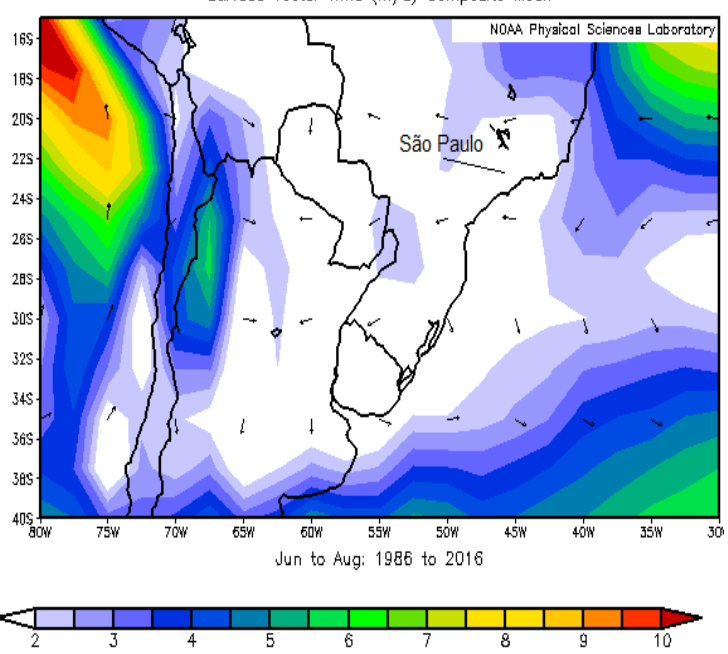

Figura 8 - Média dos ventos de superfície $(\mathrm{m} / \mathrm{s})$ e direção para a América do Sul entre 1986 e 2016 no verão (direita) e inverno (esquerda). Fonte: NCEP/NCAR 
Dessa forma, com o intuito de sintetizar as características geográficas de cada sítio sobre o potencial para acúmulo de material particulado em sua atmosfera, foi elaborado um quadro-demonstrativo das duas cidades (FIGURA 9).

\begin{tabular}{|c|c|c|c|}
\hline $\begin{array}{l}\text { Sub-área } \\
\text { geográfica }\end{array}$ & Tema & Madrid & São Paulo \\
\hline \multirow{2}{*}{$\begin{array}{l}\text { Organização da } \\
\text { Área Urbana }\end{array}$} & $\begin{array}{l}\text { Grande Concentração } \\
\text { de População }\end{array}$ & Sim & Sim \\
\hline & \begin{tabular}{ll} 
Área & \multicolumn{2}{c}{ urbana } \\
significativa em seu \\
país
\end{tabular} & Sim & Sim \\
\hline Geomorfologia & $\begin{array}{l}\text { Formação } \\
\text { Geomorforlógica }\end{array}$ & $\begin{array}{lr}\text { Rift valley } & \text { (graben e } \\
\text { horst) } & \text { com } \\
\text { depressão na área } \\
\text { de Madrid }\end{array}$ & $\begin{array}{l}\text { Colinas, terraços e } \\
\text { planícies de confluência } \\
\text { em bacia sedimentar }\end{array}$ \\
\hline \multirow{3}{*}{ Climatologia } & Efeito washout & $\begin{array}{l}\text { Mais favorável ao } \\
\text { longo do ano }\end{array}$ & $\begin{array}{l}\text { Mais atuante entre } \\
\text { outubro e março }\end{array}$ \\
\hline & $\begin{array}{l}\text { Temperatura } \quad \mathrm{e} \\
\text { pressão }\end{array}$ & $\begin{array}{l}\text { Bastante variável ao } \\
\text { longo do ano }\end{array}$ & $\begin{array}{l}\text { Menor variação ao } \\
\text { longo do ano }\end{array}$ \\
\hline & $\begin{array}{l}\text { Condições de vento } \\
\text { para acúmulo de } \\
\text { poluentes }\end{array}$ & $\begin{array}{l}\text { Maior influência no } \\
\text { verão (ventos do } \\
\text { Saara) }\end{array}$ & $\begin{array}{l}\text { Maior influência no } \\
\text { inverno (estabilidade } \\
\text { atmosférica) }\end{array}$ \\
\hline
\end{tabular}

Figura 9 - Quadro-demonstrativo dos fatores geográficos

\subsubsection{ANÁLISE DAS LEITURAS DOS RELATÓRIOS DE QUALIDADE DO AR E DAS LEGISLAÇÕES}

Durante as leituras dos relatórios de qualidade do ar de São Paulo e Madrid de 2007 a 2018, revelou-se que ao longo dos anos nas metodologias de diagnóstico a cidade espanhola criou uma forma para descartar as "intrusões do Saara", assim o material particulado que advém do deserto pôde ser descontado do diagnóstico da média anual a partir de 2012 (SERVICIO DE PROTECCIÓN DE LA ATMÓSFERA, 2013). O método leva em consideração imagens de satélite que detectam as partículas vindas do deserto e seu potencial incremento à piora da qualidade do ar, de acordo com a cidade estudada (DÍAZ, TOBÍAS e LINARES, 2012) (ÁLVAREZ-URÍA, AYUSO, et al., 2013).

São Paulo também modificou sua metodologia em 2015 passando a aplicar um fator de correção na média móvel dos últimos três anos (CETESB, 2016). Desde então as médias de ambas as cidades passaram a adotar uma tendência de queda, estabilizando-se nos últimos anos (FIGURA 10) (FIGURA 11). Ambos os relatórios apontam como causas principais as fontes móveis, 
como os automóveis, com eventuais ultrapassagens nos registros diários, predominando as épocas de verão em Madrid e inverno em São Paulo.

A quantidade de estações que formam a rede de monitoramento da qualidade do ar também sofreu alterações ao longo do período de estudo. Para Madrid houve uma queda significativa entre 2016 e 2017 para MP $_{10}$ e o aumento de uma estação em 2010 e outro aumento igual para 2018 na aferição de $\mathrm{MP}_{2,5}$. São Paulo tem variado entre 12 e 11 estações desde 2015 para $M_{10}$ e entre 5 e 6 estações desde 2015 para MP $_{2,5}$ (FIGURA 12).

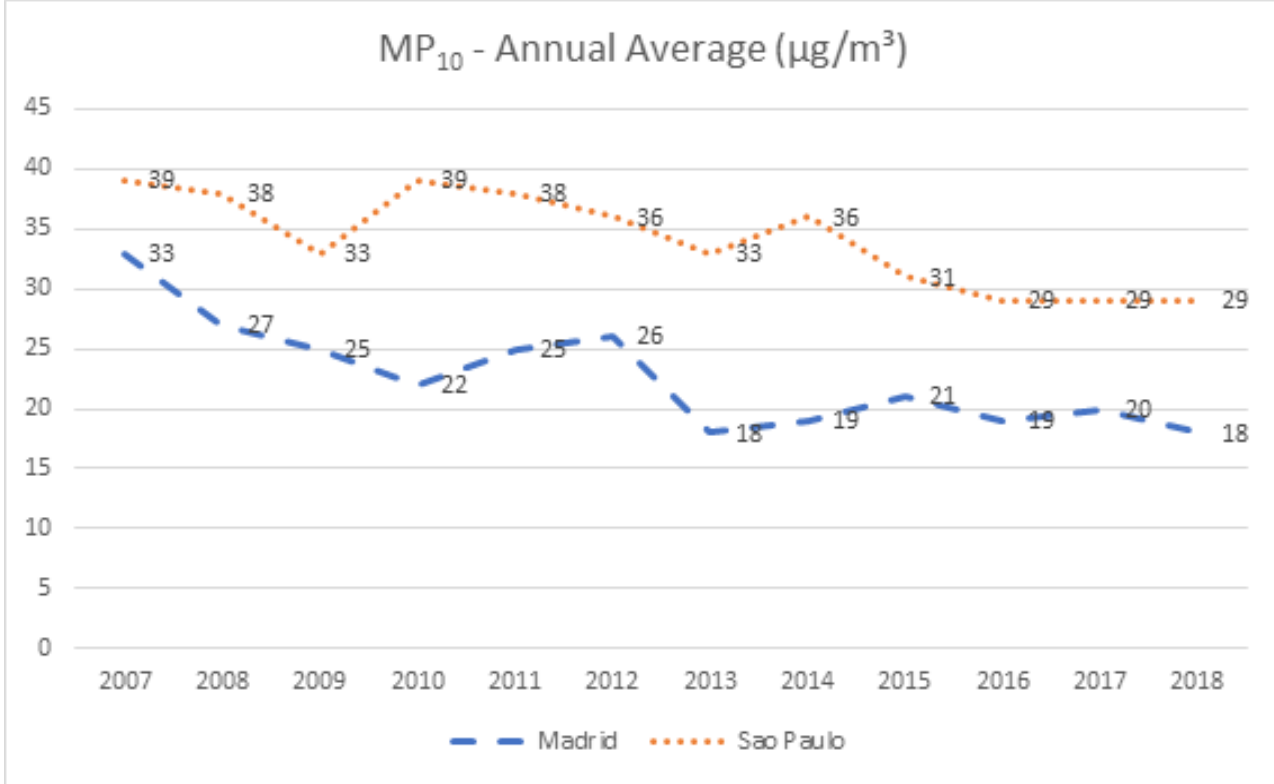

Figura 10 - Média anual de $\mathrm{MP}_{10}$ para São Paulo e Madrid

$$
\mathrm{MP}_{2,5} \text { - Annual Average }\left(\mu \mathrm{g} / \mathrm{m}^{3}\right)
$$

25

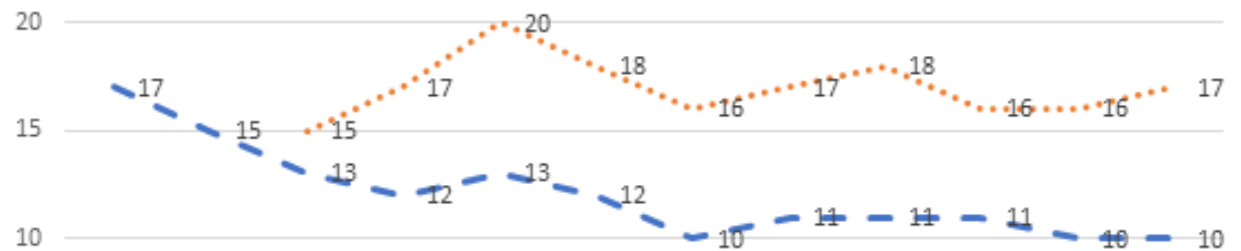

5

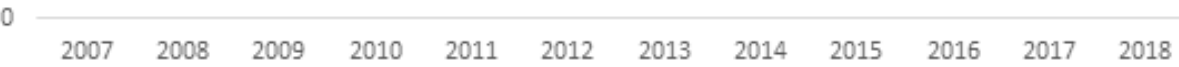

- Madrid ....... SãoPaulo

Figura 11 - Média anual de $\mathrm{MP}_{2,5}$ para São Paulo e Madrid 


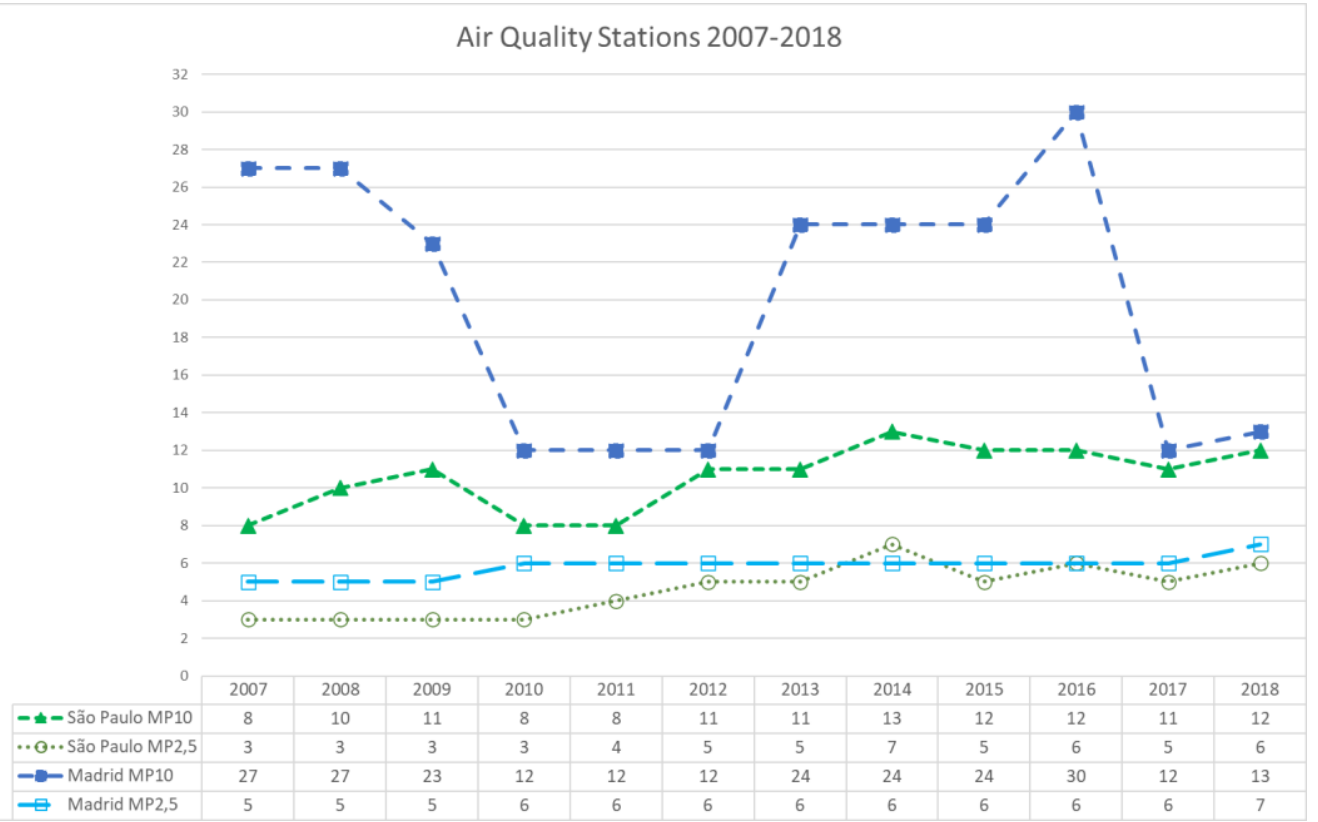

Figura 12 - Quantidade de estações de qualidade do ar

A partir de 2010, a estação Plaza Luca de Tena, localizada no distrito de Arganzuela, ponto mais poluído de Madrid nos anos de 2007 a 2009, foi fechada (SERVICIO DE CALIDAD DEL AIRE, 2011). A estação se localizava numa parte baixa em um vale em uma das curvas do Rio Manzanares, próximo ao centro da cidade. A partir de 2012 toda a rede de estações de qualidade do ar de Madrid recebe o certificado ISO 9001 e o 14001 (SERVICIO DE PROTECCIÓN DE LA ATMÓSFERA, 2013).

Consultando os sítios e os relatórios de qualidade do ar e posteriormente os limites de tolerância do material particulado disponibilizado nos relatórios entre 2007 e 2018, verificou-se que as cidades estavam obedecendo os níveis de concentração de poluentes do ar, ainda que pontualmente pudesse haver alguma ultrapassagem, e ainda que dentro dos limites de tolerância, que era de uma vez ao ano para São Paulo e até 35 vezes ao ano em Madrid (AYUNTAMIENTO DE MADRID, 2010) (CETESB, 2011).

Sobre os limites de material particulado tolerado, São Paulo também mudou a partir de 2013, tornando-se mais rígida que a regra nacional: dos 150 $\mu \mathrm{g} / \mathrm{m}^{3}$ de limite diário, passa para 120 , e a média anual de 50 para $40 \mu \mathrm{g} / \mathrm{m}^{3}$. Os novos limites para $\mathrm{MP}_{2,5}$ passam a ser de $60 \mu \mathrm{g} / \mathrm{m}^{3}$ a média diária e 20 $\mathrm{\mu g} / \mathrm{m}^{3}$ a anual - Decreto Estadual 59.113/2013 (SÃO PAULO, 2013).

Ressalta-se que os limites recomendados pela OMS para $\mathrm{MP}_{2,5}$ é de 10 $\mu \mathrm{g} / \mathrm{m}^{3}$ (anual) e Madrid limita em $25 \mu \mathrm{g} / \mathrm{m}^{3}$ de média anual. Para $\mathrm{MP}_{10}$, a OMS recomenda $20 \mu \mathrm{g} / \mathrm{m}^{3}$ e as leis espanholas permitem $40 \mu \mathrm{g} / \mathrm{m}^{3}$ de média anual (ORGANIZAÇÃO MUNDIAL DE SAÚDE / ORGANIZAÇÃO PAN AMERICANA DA SAÚDE, 2018) (CETESB, 2019) (DIRECCIÓN GENERAL DE SOSTENTABILIDAD Y CONTROL AMBIENTAL, 2018).

Com essa situação, os limites de poluição atmosférica estão todos de acordo com os impostos pelos respectivos governos. No entanto, como verificou-se, estão longe do recomendado pela OMS e ainda, o aumento da 
poluição atmosférica nessas cidades ocorre de forma significativa em situações pontuais e em épocas preferenciais do ano.

Esses episódios agudos geralmente registram valores mais altos (acima do limite diário de $50 \mu \mathrm{g} / \mathrm{m}^{3}$ ) em situações de menos pluviosidade ou extremos acima de $400 \mu \mathrm{g} / \mathrm{m}^{3}$, quando há eventos externos (como as intrusões do Saara ou estabilidade atmosférica prolongada), verificado nos dois tipos de material particulado $\left(M_{10}\right.$ e $\left.M_{2,5}\right)$ (DIRECCIÓN GENERAL DE SOSTENTABILIDAD $Y$ CONTROL AMBIENTAL, 2018).

\section{CONCLUSÃO}

Nesse estudo pode-se observar que as áreas escolhidas são significativas regionalmente e com grande potencial de emissão de poluição, apesar da sazonalidade das emissões ao longo do ano.

Madrid, por sua vez, tende a concentrar particulados nas estações de inverno e verão, a primeira pelo estacionamento dos anticiclones que deixam o ar estável, que quando associados com o maior número de aquecedores em funcionamento e os deslocamentos diários na cidade, pioram a qualidade do ar na cidade. No verão, a piora se dá com a chegada do ar Saariano carregado de particulados do deserto além de estabilidade atmosférica. No entanto, as intrusões Saarianas são descontadas para a média de qualidade do ar da cidade espanhola nos relatórios anuais.

Em São Paulo a situação mais crítica é no outono e inverno pelas mesmas razões: maior estabilidade do ar causada por anticiclone, apesar de não haver tantas caldeiras e aquecedores para o ambiente indoor como na Europa. Por outro lado, a cidade é maior, os deslocamentos são mais longos e, principalmente, apresenta diminuição de precipitação. Com a adoção das médias móveis dos fatores meteorológicos, apesar do crescimento urbano, a qualidade do ar está estável, segundo os relatórios.

Ambas as cidades apresentam um arranjo clássico de formação centroperiferia, desde a segunda metade do século $X X$, onde o centro é dominado pelo setor produtivo e a periferia residencial. Essa formação estimula o deslocamento diário pendular utilizando veículos automotores e esses, por serem fontes móveis de emissões de poluentes, são também os principais contribuintes antropogênicos para a queda da qualidade do ar.

A localização de Madrid em cotas medianas de La Sierra, com seus pontos mais altos a norte e noroeste favorece a circulação normal dos ventos (de oeste). Porém quando chegam os anticiclones de inverno (de norte) ou os ventos Saarianos (de sul), os índices de poluição aumentam no centro do país.

Quanto ao relevo paulistano destaca-se a configuração geomorfológica do estado de São Paulo que é composta por um conjunto de colinas que possuem grande influência na ocupação urbana, definindo o traçado da malha viária e a disposição das áreas habitacionais, preferencialmente nas periferias.

Estas características apresentadas pelas duas cidades contribuem para a acumulação e retenção de material particulado a partir das chamadas bacias aéreas, além disso, o uso do solo e as rodovias contribuem para a liberação e concentração de poluentes atmosféricos. 
Apesar de segundo a legislação e os acordos que cada Estado é signatário, ocorre que principalmente após as mudanças que elas fizeram nas suas metodologias, estão todas dentro dos limites com relação a concentração de poluentes. Mas destaca-se que a situação é diferente se considerarmos o que a Organização Mundial de Saúde recomenda, estando tanto São Paulo quanto Madrid fora das especificações.

O presente estudo tem como ponto forte a utilização de diferentes abordagens e fontes de dados para examinar fatores que influenciam a poluição do ar em duas importantes metrópoles. No entanto, a tendência notada de estabilidade dos níveis de poluição será mais bem apurada com a continuidade do monitoramento, ampliando a base temporal de dados.

Para estudos futuros, sugere-se aumentar a escala temporal, a comparação das condições atmosféricas em que ocorrem os picos de poluição nas diferentes cidades e manter a abordagem holística e multidisciplinar para compreender as ações mitigadoras dos órgãos competentes.

\section{AGRADECIMENTOS}

CAPES - Coordenação de Aperfeiçoamento de Pessoal de Nível Superior

\section{REFERÊNCIAS BIBLIOGRÁFICAS}

AB'SABER, A. Geomorfologia do Sítio Urbano de São Paulo. 2. ed. Cotia: Ateliê Editorial, 2007.

ÁLVAREZ-URÍA, P. T. et al. Salud y sostenibilidad: efectos de la calidad del aire urbano. Madrid: Fundación Mapfre, v. 1, 2013. Disponivel em: <https://www.researchgate.net/publication/280547135_Salud_y_Sostenibilidad _Efectos_de_la_Calidad_del_Aire_Urbano>. Acesso em: 20 maio 2020.

AMATO-LOURENÇO, L. F. et al. The influence of atmospheric particles on the elemental content of vegetables in urban gardens of Sao Paulo, Brazil. Environmental Pollution, 216, 2016. 125-134.

AYUNTAMIENTO DE MADRID. Catálogo de Datos. Portal de datos abiertos del Ayuntamiento de Madrid, 2010. Disponivel em: <https://datos.madrid.es/portal/site/egob>. Acesso em: 20 out. 2019.

AYUNTAMIENTO DE MADRID. Datos Abiertos del Ayuntamiento de Madrid. Portal de datos abiertos del Ayuntamiento de Madrid, 2010. Disponivel em: <https://datos.madrid.es/portal/site/egob>. Acesso em: 03 out. 2019.

AYUNTAMIENTO DE MADRID. Portal Web de Calidad del Aire del Ayuntamiento de Madrid. Memorias anuales de calidad del aire, 2010. Disponivel em: <http://www.mambiente.madrid.es/opencms/opencms/calaire/Publicaciones/Me morias.html>. Acesso em: 05 out. 2019.

CASTRO, M. G. S. Chuva ácida na cidade de São Paulo. São Paulo: Universidade de São Paulo, 1993.

CAVALCANTI, I. F. A. et al. Tempo e Clima no Brasil. 2. ed. São Paulo: Oficina de Textos, 2009. 464 p. 
CETESB. Relatório de Qualidade do Ar. Secretaria do Meio Ambiente. São Paulo, p. 132. 2002.

CETESB. Relatório de qualidade do ar de São Paulo 2008. São Paulo, p. 354. 2009.

CETESB. Configuração da Rede Automática. Configuração e localização das estações, 2011. Disponivel em: <https://cetesb.sp.gov.br/ar/configuracao-darede-automatica/>. Acesso em: 02 abr. 2017.

CETESB. Qualidade do ar no estado de São Paulo 2015. CETESB - Companhia Ambiental do Estado de São Paulo. São Paulo. 2016.

CETESB. Qualidade do ar no estado de São Paulo 2018. CETESB - Companhia Ambiental do Estado de São Paulo. São Paulo, p. 214. 2019.

CLIMATE DATA. Dados Climáticos de Cidades Mundiais. Temperaturas e Precipitações Médias, 2006. Disponivel em: <https://pt.climate-data.org/>. Acesso em: 10 jan. 2019.

DÍAZ, J.; TOBÍAS, A.; LINARES, C. Saharan dust and association between particulate matter and case-specific mortality: a case-crossover analysis in Madrid (Spain). Environmental Health, v. 11, n. 11, p. 1-6, 08 mar. 2012. Disponivel em: <https://ehjournal.biomedcentral.com/track/pdf/10.1186/1476069X-11-11>. Acesso em: 03 abr. 2020.

DIRECCIÓN GENERAL DE SOSTENTABILIDAD Y CONTROL AMBIENTAL. Calidad del Aire 2018. Ayuntamiento de Madrid. Madrid. 2018.

EMBRAPA. Acervo. Embrapa Monitoramento por Satélite, 2005. Disponivel em: <https://www.cnpm.embrapa.br/projetos/acervo.html>. Acesso em: 2017.

EUROPEAN COMMISSION. Ambient Air Quality and Cleaner Air for Europe. DIRECTIVE 2008/50/EC, Bruxelas, 21 maio 2008. Disponivel em: <http://ec.europa.eu/environment/air/quality/standards.htm>. Acesso em: 25 set 2018.

FARIAS, H. S. Bacias Aéreas: Uma proposta metodológica para o estudo da qualidade do ar em áreas influenciadas pelo relevo. Revista Brasileira de Climatologia, Rio de Janeiro, v. 12, p. 48-60, Jan 2013. Disponivel em: <https://revistas.ufpr.br/revistaabclima/article/view/30081/21506>. Acesso em: 15 jan. 2020.

FERREIRA, T. M. et al. Effects of Particulate Matter and Its Chemical Constituents on Elderly Hospital Admissions Due to Circulatory and Respiratory Diseases. International Journal of Environmental Research and Public Health, 2016. $11 . \quad$ Disponível em: https://www.ncbi.nlm.nih.gov/pmc/articles/PMC5086686/pdf/ijerph-1300947.pdf.

FRUEHAUF, G. L. C. A deterioração da qualidade do ar e clima na região metropolitana de São Paulo. São Paulo: Tese de doutorado apresentada ao Departamento de Geografia, 1998. Disponivel em: <www.teses.usp.br>. Acesso em: 15 jun. 2020.

GARCÍA ALVARADO, J. M.; SOTELO NAVALPOTRO, J. A. La España de las Autonomías. Madrid: Síntesis, 1999. 
GARCIA, F. F.; COCA, M. A. A.; GÓMEZ, A. L. La influencia del relieve en la isla de calor de Madrid: las vaguadas del Manzanares y del abroñigal. Estudios Geográficos, Madrid, 57, Jul-Set 1996. 473-494. Disponivel em: <http://estudiosgeograficos.revistas.csic.es/index.php/estudiosgeograficos/articl e/view/682>. Acesso em: 08 jul. 2020.

GIL OLCINA, A.; OLCINA CANTOS, J. Tratado de Climatologia. Sant Vincent de Raspeig: Universitat D'Alicant, 2017.

GÓMEZ-MORENO, F. J. et al. Annual evolution and generation mechanisms of particulate nitrate in Madrid. Atmos. Environ, Amsterdã, v. 41, p. 394-406, jan. 2007.

em: <https://www.sciencedirect.com/science/article/abs/pii/S1352231006008235>. Acesso em: 01 ago. 2020.

GOUVEIA, N. et al. Hospitalizações por causas respiratórias e cardiovasculares associadas à contaminação atmosférica no Município de São Paulo, Brasil. Cadernos de Saúde Pública, Rio de Janeiro, 22, Dezembro 2006. Disponível em: http://www.scielosp.org/scielo.php?script=sci_arttext\&pid=S0102311X2006001200016\&lang $=$ pt.

HAMRA, G. B. et al. Outdoor particulate matter exposure and lung cancer: a systematic review and meta-analysis. Environ Health Perspectives, New York, set 2014. 906-911. Disponível em:.

IBGE. Censo Brasileiro 2010. Rio de Janeiro: IBGE, 2011.

INSTITUTO NACIONAL DE ESTADÍSTICA DE ESPAÑA. Población por Municípios. INSTITUTO NACIONAL DE ESTADÍSTICA DE ESPAÑA, 2018. Disponivel em: <https://www.ine.es/dyngs/INEbase/es/categoria.htm?c=Estadistica_P\&cid=12 54734710990>. Acesso em: 2019 out. 22.

LANDSBERG, H. E. The Urban Climate. London: Academic Press, v. 28, 1983.

LOOMIS, D.; HUANG, W.; CHEN, G. The International Agency for Research on Cancer (IARC) evaluation of the carcinogenicity of outdoor air pollution: focus on China. Chin J Cancer, New Jersey, 33, abr. 2014. 189-196. Disponivel em: <https://www.ncbi.nlm.nih.gov/pmc/articles/PMC3975184/>. Acesso em: 30 mar. 2020.

MENDONÇA, F.; DANNI-OLIVEIRA, I. M. Climatologia: noções básicas e climas do Brasil. São Paulo: Oficina de Textos, 2009.

MENDONÇA, F.; MONTEIRO, C. A. F. Clima Urbano. São Paulo: Contexto, 2003.

MERCOSUL. Acordo-Quadro Sobre Meio Ambiente do Mercosul. Mercosul. Assunção, p. $1-5.2001$. Disponível em: http://www.mercosur.int/msweb/Normas/Tratado\%20e\%20Protocolos/Dec_002 _001_Acordo\%20Meio\%20Ambiente_MCS_Ata\%201_01.pdf Acessado em: 04/02/2016.

NARDOCCI, A. C. et al. Poluição do $\mathrm{Ar}$ e Doenças Respiratórias e Cardiovasculares: estudo de séries temporais em Cubatão, São Paulo, Brasil. Caderno de Saúde Pública, Rio de Janeiro, set 2013. 1867-1876.

NATIONAL AERONAUTICS AND SPACE ADMINISTRATION. Visible Earth. Earth at Night (Black Marble) 2016 Color Maps, 2009. Disponivel em: 
<https://visibleearth.nasa.gov/images/144898/earth-at-night-black-marble2016-color-maps>. Acesso em: 25 out. 2019.

NEWELL, K. et al. Cardiorespiratory health effects of particulate ambient air pollution exposure in low-income and middle-income countries: a systematic review and meta-analysis. The Lancet Planetary Health, London, dez 2017. 368380. Disponível em:.

NOAA. Climate Analysis and Plotting Tools. Office of Oceanic and Atmospheric Research, 2013. Disponivel em: <https://www.esrl.noaa.gov/psd/cgibin/data/getpage.pl>. Acesso em: 21 out. 2019.

OKE, T. R. Boundary Layer Climates. 2a. ed. London \& New York: Routledge, 1987.

OLIVEIRA, J. L. F. Análise espacial e modelagem atmosférica: contribuições ao gerenciamento da qualidade do ar da bacia aérea III da região metropolitana do Rio de Janeiro. Rio de Janeiro: Tese de Doutorado - COPPE - Universidade Federal do Rio de Janeiro, 2004. 144 p. Disponível em:.

ORGANIZAÇÃO MUNDIAL DA SAÚDE. World Health Organization. Air Pollution, 2005. Disponivel em: <http://www.who.int/topics/air_pollution/en/>. Acesso em: 04 fev 2016.

ORGANIZAÇÃO MUNDIAL DE SAÚDE / ORGANIZAÇÃO PAN AMERICANA DA SAÚDE. La Nueva Base de Datos de Calidad del Aire y Salud de la OMS. OPAS / OMS. Genebra. 2018.

ORGANIZAÇÃO MUNDIAL DE SAÚDE. Economic cost of deaths from air pollution (outdoor and indoor) per country, as a percentage of GDP WHO European Region, 2010. Organização Mundial da Saúde. Genebra, p. 1. 2011.

ORGANIZAÇÃO MUNDIAL DE SAÚDE. World Health Organization. Ambient (outdoor) air quality and health, 02 mai 2018. Disponivel em: <http://www.who.int/news-room/fact-sheets/detail/ambient-(outdoor)-airquality-and-health>. Acesso em: 14 mar 2009.

PEDRAZA, J. et al. El Sector Central de la Sierra de Guadarrama: singularidad paisajística y problemática de gestión. In: PÉREZ-GONZÁLEZ, A.; VEGAS, J.; MACHADO, M. J. Aportaciones a la Geomorfología de España en el Início del Tercer Milenio. Madrid: Instituto Geológico y Minero de España, 2002. Cap. 7.8, p. 441-447. Disponivel em: <https://dialnet.unirioja.es/servlet/articulo?codigo $=1196624>$. Acesso em: 20 jan. 2020.

PELOGGIA, A. O Homem e o Ambiente Geológico: geologia, sociedade e ocupação urbana no Município de São Paulo. 2. ed. São Paulo: Xamã, 1998.

PEREIRA, F. A. et al. Urban, traffic- related particles and lung tumors in urethane treated mice. Clinics, São Paulo, 66, Junho 2011. 1051-1054. Disponível em: https://www.ncbi.nlm.nih.gov/pubmed/22763046.

PREFEITURA DA CIDADE DE SÃO PAULO. Características Gerais do Município, $2004 . \quad$ Disponivel em: <https://www.prefeitura.sp.gov.br/cidade/secretarias/upload/arquivos/secretari as/meio_ambiente/projetos_acoes/0004/capitulo2.pdf $>$. Acesso em: 14 jan. 2020. 
PREFEITURA DE SÃO PAULO. Mapa Digital da Cidade de São Paulo. GEOSampa, $2013 . \quad$ Disponivel em: <http://geosampa.prefeitura.sp.gov.br/PaginasPublicas/_SBC.aspx>. Acesso em: 2017.

RÍOS, B. Bruselas lleva a España ante la Justicia europea por la contaminación. El Mundo, Madrid, 25 jul. 2019. Disponivel em: <https://www.elmundo.es/madrid/2019/07/25/5d398389fc6c8363408b45ad.ht $\mathrm{ml}>$. Acesso em: 03 out. 2019.

SALDIVA, P. Vida Urbana e Saúde. São Paulo: Contexto, 2018.

SALTHAMMER, T. et al. Impact of operating wood-burning fireplace ovens on indoor air quality. Chemosphere, London, maio 2014. 205-211. Disponivel em: <https://www.sciencedirect.com/science/article/pii/S0045653513016573>. Acesso em: 25 jan. 2020.

SÃO PAULO. Decreto 59.113/13. Estabelece novos padrões de qualidade do ar e dá providências correlatas, São Paulo, 23 abr 2013. Disponivel em: <https://www.al.sp.gov.br/repositorio/legislacao/decreto/2013/decreto-5911323.04.2013.html>. Acesso em: 17 jul 2018.

SERVICIO DE CALIDAD DEL AIRE. Calidad del Aire Madrid 2010. Portal Web de Calidad del Aire del Ayuntamiento de Madrid. Madrid. 2011.

SERVICIO DE PROTECCIÓN DE LA ATMÓSFERA. Calidad del Aire Madrid 2012. Portal Web de Calidad del Aire del Ayuntamiento de Madrid. Madrid. 2013.

SERVICIO DE PROTECCIÓN DE LA ATMÓSFERA. Calidad del Aire Madrid 2012. Portal Web de Calidad del Aire del Ayuntamiento de Madrid. Madrid. 2013.

SILVA JUNIOR, R. S. Sensibilidade na estimativa da concentração de poluentes fotoquímicos com a aplicação de diferentes parametrizações de camada limite planetária utilizando o modelo de qualidade do ar WRF/Chem. São Paulo: Instituto de Astronomia, Geofísica e Ciências Atmosféricas, Universidade de São Paulo, 2009. Disponivel em: <www.teses.usp.br>. Acesso em: 20 jul. 2020.

SILVA JUNIOR, R. S.; MARTILLI, A.; SILVA, E. H. L. Efeito da Urbanização sobre a Dispersão de Poluentes e Formação de Ilha de Calor. Revista Brasileira de Climatologia, Curitiba, v. 27, p. 34-56, 10 jul. 2020. Disponivel em: <https://revistas.ufpr.br/revistaabclima/article/view/69398/41101>. Acesso em: 05 ago. 2020.

STEINKE, E. T. Climatologia Fácil. São Paulo: Oficina de Textos, 2012.

TARIFA, J. R.; AZEVEDO, T. R. Os Climas na Cidade de São Paulo: teoria e prática. São Paulo: FFLCH/ USP, 2001.

TORRES, F. T. P.; MARTINS, L. A. Fatores que Influenciam na concentração do material particulado na cidade de Juiz de Fora (MG). Caminhos da Geografia, Uberlândia, v. 16, p. 23-39, 18 set. 2005. Disponivel em: <http://www.seer.ufu.br/index.php/caminhosdegeografia/article/view/15403/87 $01>$. Acesso em: 03 jul. 2020.

UNITED NATIONS. Kyoto Protocol to the United Nations Framework. Conference on Climate Change. New York: United Nations. 1998. p. 1-21. 
VIEIRA-FILHO, M. S.; LEHMANN, C.; FORNARO, A. Influence of Local Sources and Topography on Air Quality and Rainwater Composition in Cubatão and São Paulo, Brazil. Atmospheric Environment, London, 101, jan 2015. 200-208. Disponível

em: http://www.sciencedirect.com/science/article/pii/S135223101400884X Acessado em: 31/11/2015.

WORLD HEALTH ORGANIZATION. Motor Vehicle Air Pollution: public health impact and control measures. Genebra, p. 250. 1992.

YOSHINO, M. M. Thermal Belt and Cold Air Drainage on the Mountain Slope and Cold Air Lake in the Basin at Quiet, Clear Night. GeoJournal, Tsukuba, v. 8, p. 235-250, 1984.

Disponivel

em: <https://link.springer.com/article/10.1007/BF00446473>. Acesso em: 10 jun. 2020. 